$05,13,12$

\title{
Локальная кристаллизация под действием одиночного лазерного импульса в аморфных микропроводах PrDyFeCoB
}

\author{
(ㅇ Д.В. Королев ${ }^{1}$, В.П. Пискорский ${ }^{1}$, Р.А. Валеев ${ }^{1}$, О.В. Коплак ${ }^{2,9}$, Р.Б. Моргунов ${ }^{2,3}$ \\ ${ }^{1}$ Всероссийский научно-исследовательский институт авиационных материалов, \\ Москва, Россия \\ ${ }^{2}$ Институт проблем химической физики РАН, \\ Черноголовка, Россия \\ ${ }^{3}$ Тамбовский государственный технический университет, \\ Тамбов, Россия \\ I E-mail: o.koplak@gmail.com
}

Поступила в Редакцию 11 апреля 2021 г.

В окончательной редакции 11 апреля 2021 г.

Принята к публикации 11 апреля 2021 г.

B аморфных микропроводах $\operatorname{PrDyFeCoB}$, подвергнутых действию одиночного лазерного импульса с энергией $1 \mathrm{~mJ}$, длительностью $120 \mathrm{~ns}$ и длиной волны $1040 \mathrm{~nm}$, обнаружены участки с нанокристаллической структурой, содержащей фазы мягкого ферромагнетика $(\mathrm{PrDy})_{1}(\mathrm{FeCoB})_{2},(\mathrm{PrDy})_{2}(\mathrm{FeCoB})_{1},(\mathrm{PrDy})_{1}(\mathrm{FeCoB})_{4} \mathrm{~B}_{1}$ и основную магнитную фазу $(\operatorname{PrDy})_{2}(\mathrm{FeCoB})_{14} \mathrm{~B}_{1}$. Различие между вакуумным длительным отжигом всего образца и локальным лазерным нагревом части его поверхности заключается в том, что при длительном отжиге возникают зерна фазы $(\mathrm{PrDy})_{2}(\mathrm{FeCoB}){ }_{14} \mathrm{~B}_{1}$ размером $800 \mathrm{~nm}$, тогда, как при лазерном облучении размер зерен этой фазы составляет 10-20 nm. Чередование кристаллизованных зон вдоль оси микропровода обеспечивает его магнитомодулированную структуру с перпендикулярной компонентой намагниченности. Локальные петли магнитного гистерезиса, записанные с помощью микроскопа Керра в участках, подвергнутых лазерному облучению, демонстрируют большее поле магнитной анизотропии 500 Ое, чем в необлученных участках 10 Oе.

Ключевые слова: аморфные микропровода, редкоземельные сплавы, лазерное облучение, магнитные фазы, магнитомодулированные структуры.

DOI: 10.21883/FTT.2021.08.51161.083

\section{1. Введение}

Сплавы группы $R e-T M$-В $(R e-$ редкоземельные металлы, $T M$ - переходные металлы, В - бор) являются основой для наиболее сильных постоянных магнитов c самой высокой запасенной магнитной энергией и остаточной намагниченностью. Технические применения этих сплавов в макроскопических устройствах (генераторах, электродвигателях, томографах и др.) связаны с наличием тетрагональной фазы $(\mathrm{PrDy}){ }_{2}(\mathrm{FeCoB}){ }_{14} \mathrm{~B}_{1}$ (фаза 2-14-1) и искусством ее направленного формирования таким образом, чтобы ее зерна были ориентированы в заданном направлении и изолированы друг от друга немагнитной межзеренной оболочкой, сдерживающей смещение доменных стенок. При этом обычно стремятся подавить рост фаз, которые являются мягкими ферромагнетиками при комнатной температуре, например, $(\operatorname{PrDy})_{1}(\mathrm{FeCoB})_{2}$ (фаза 1-2) и $(\mathrm{PrDy})_{1}(\mathrm{FeCoB})_{4} \mathrm{~B}_{4}$ (фаза 1-4-4). В макроскопических магнитах процессы роста упомянутых фаз в стационарных условиях отжига в вакуумной печи детально изучены и лежат в основе получения совершенных магнитов из аморфной фазы.

В последние годы интенсивно развивается разработка микромагнитов (в частности микропроводов), которые могут служить в качестве частиц для гипертермии, маг- нитных микропинцетов в медицине и биологии, сенсоров магнитного поля, механически напряжений, деформации и температуры [1-3]. Хотя основное количество работ в этой области сделано на основе микропроводов переходных металлов $\mathrm{FeSi}, \mathrm{FeCoSi}, \mathrm{CoSi}, \mathrm{FeCoSiB}$ [4-6], использование микропроводов $R e-T M$-В для тех же практических задач кажется весьма привлекательным. В частности, высокая коэрцитивная сила и остаточная намагниченность редкоземельных сплавов необходимы для эффективного использования микромагнитов в качестве магнитных манипуляторов, а на порядок большая магнитострикция, чем в переходных металлах, обещает значительный рост магнитоимпедансного эффекта и соответствующей чувствительности вышеупомянутых сенсоров, основанных на магнитострикции. В литературе сообщалось о получении микропроводов и микромагнитов заданной формы на основе сплава $\mathrm{NdFeB}[7,8]$ и сплава PrDyFeCoB [9-10], а также о высокоэффективных магнитных микропинцетах с увеличенной магнитной силой для биомедицинских применений [11].

Одной из задач дизайна микромагнитных устройств является получение магнитомодулированных линейных объектов, которые могли бы служить в качестве ротора линейных микродвигателей, необходимых для медицинских микророботов [12], а также в качестве устройств 
селекционирования и позиционирования магнитомеченных биологических объектов, способных перемещаться в периодическом магнитном рельефе под действием внешнего переменного магнитного поля [13]. Одним из эффективных методов программируемой инженерии магнитных микроструктур является лазерная аддитивная технология, используемая таким образом, что узкий микронный пучок лазерного излучения локально нагревает выбранные участки микромагнита в течение короткого времени. Это позволяет производить локальную кристаллизацию исходно аморфного ферромагнетика, создавая на его поверхности нужный рисунок с заданным распределением намагниченности. Такие эксперименты были успешно проведены с объемными магнитами и пленками $\mathrm{NdFeB} \mathrm{[14-18].} \mathrm{Было} \mathrm{установ-}$ лено, что аморфный сплав $\mathrm{NdFeB}$ трансформируется в фазу 2-14-1 с высокой коэрцитивной силой в локальных участках, подвергнутых лазерному облучению. При этом условия теплового обмена определялись макроскопическими размерами объемных образцов и пленок. Работы, где локальная лазерная кристаллизация исследована в микромагнитах группы $R e-T M-\mathrm{B}$, редки в литературе. Вместе с тем, быстрый нагрев коротким лазерным импульсом мог бы быть обеспечен именно в магнитах микроскопических размеров, которые сопоставимы по диаметру с диаметром лазерного пучка, а теплообмен ограничен их малыми размерами. Хотя имеются многочисленные примеры успешного развития исследований поверхности металлов и полупроводников, модифицированных лазерным излучением, вынужденная локальная кристаллизация и фазовые переходы под действием короткого лазерного импульса не получили до сих пор исчерпывающего объяснения. Это связано с тем, что процессы, инициируемые лазером не сводятся к одному лишь нагреву кристаллической решетки, а требуют учета акустического воздействия, возбуждаемого коротким лазерным импульсом, учета горячих электронов проводимости, высокого градиента температуры, термических напряжений, холодной абляции и возможных химических реакций (например, окисление), значительно изменяющих свойства материала. Все эти особенности экспериментально доказаны при облучении аморфных и кристаллических металлов и полупроводников одиночными импульсами, однако в ферромагнитных редкоземельных сплавах подобных экспериментов сравнительно мало. Поэтому интерес к проблеме, помимо практического развития аддитивных технологий микромагнитов, возникает еще и в плоскости фундаментальных проблем определения состояний ферромагнетика, управляемых и индуцируемых короткими лазерными импульсами. В наших экспериментах был использован одиночный импульс ИК-лазера, длительность которого $120 \mathrm{~ns}$ ненамного превышала длительность тепловой релаксации в металле и полностью исключала диффузионные процессы за время нагрева.
Цель настоящей работы заключалась в подборе такого режима лазерного облучения аморфных микропроводов PrDyFeCoB, который бы приводил к локальной кристаллизации в области разогрева под действием одиночного импульса, а также в исследовании фазового и химического состава и магнитных свойств областей микропроводов, модифицированных лазерным облучением.

\section{2. Образцы и методика измерений}

В настоящей работе были использованы микропровода, полученные методом сверхбыстрого охлаждения капли расплава $\mathrm{PrDyFeCoB}$ на вращающемся медном цилиндре, охлаждаемом водой. Капля расплава была получена на грани спеченного магнита $\mathrm{PrDyFeCoB}$ путем локального разогрева электронным пучком. Оценка скорости охлаждения расплава при линейной скорости вращения цилиндра $50 \mathrm{~m} / \mathrm{s}$ дает $\sim 10^{6} \mathrm{~K} / \mathrm{s}$. Микропровода были длиной 10-20 mm и диаметром 50-100 $\mu \mathrm{m}$. Для оценки химического и фазового состава микропроводов были использованы методы просвечивающей электронной микроскопии (ТЕМ), рентгено-дифракционного анализа (РФА), рентгеновская фотоэлектронная спектроскопия (XPS) и энергодисперсионные спектры (EDX), полученные в сканирующем электронном микроскопе (SEM).

Электронно-дифракционные изображения были получены с помощью микроскопа HR TEM JEOL при ускоряющем напряжении $100 \mathrm{kV}$ на ламелях, вырезанных из облученных лазером и необлученных частей микропровода (рис. 1,a). При этом исходные микропровода демонстрировали в основном аморфную структуру, идентифицируемую по непрерывному гало на электронной дифрактограмме (рис. $1, b)$.

При этом в исходных микропроводах либо не наблюдалась кристаллическая структура (рис. 1,c), либо встречались редкие наноразмерные включения, принадлежащие фазе 2-14-1, что было установлено по периоду кристаллической решетки $0.9 \pm 0.03 \mathrm{~nm}$, близкому к величине $0.887 \mathrm{~nm}$, известной, как период для кристаллографического направления $a$ этой фазы из литературы (рис. 1, $d$ ).

Рентгеноструктурный анализ проводили для измельченных в порошок образцов на рентгеновском дифрактометре D/MAX-2500 фирмы „Rigaku“ в монохроматическом излучении трубки $\mathrm{CuK}_{\alpha}$ в геометрии Брегга-Брентано. Расшифровка дифрактограмм проведена с помощью специализированной программы HighScore и структурной базы данных PDF-2. Рентгеновская съемка проводилась в диапазоне углов $2 \theta=20-100^{\circ}$. Спектр рентгеновской дифракции исходных микропроводов помимо дифракционных максимумов содержал гало, принадлежащее аморфной фазе (рис. 2,a). Отжиг этих образцов при $900^{\circ} \mathrm{C}$ приводил к исчезновению гало (рис. $2, b$ ), что также хорошо известно из литературы для сплава, сходного с исследуемым в нашей работе DyFeB [19]. 


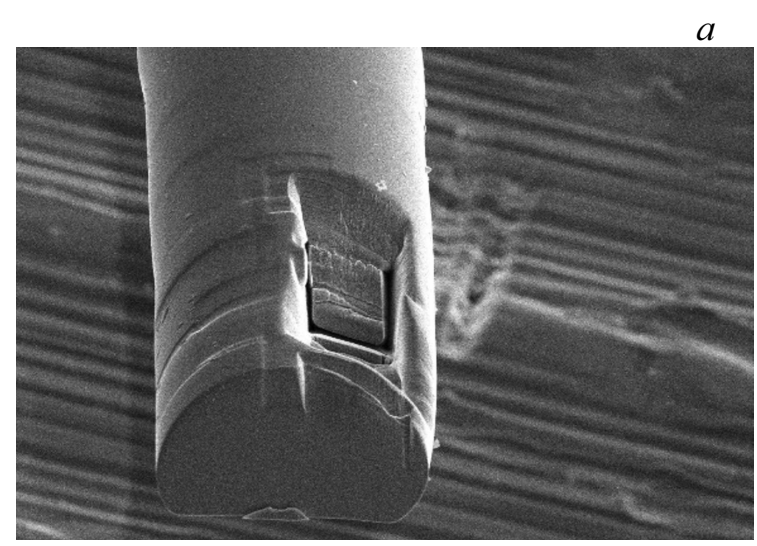

$50 \mu \mathrm{m}$

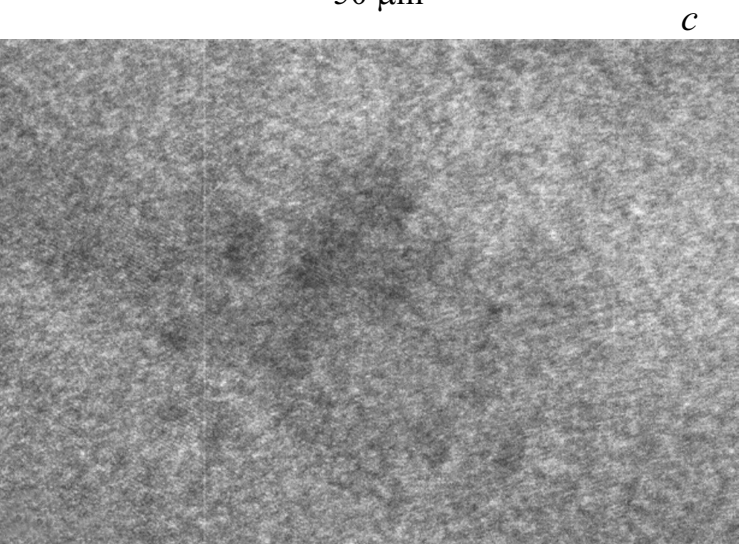

$5 \mathrm{~nm}$

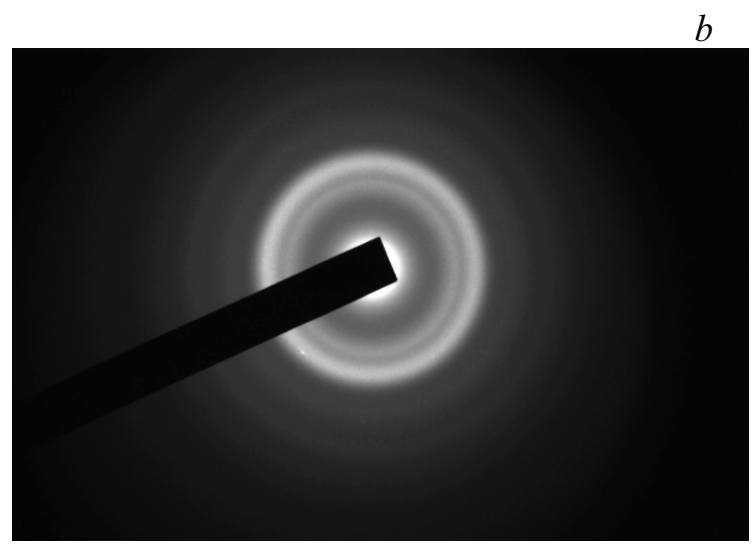

$51 \mathrm{~nm}$

$d$

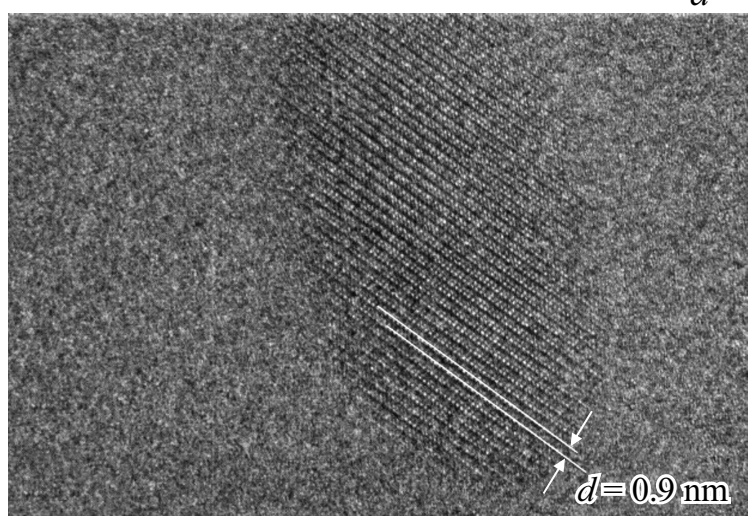

$5 \mathrm{~nm}$

Рис. 1. Изображение исходного микропровода с вырезанной ламелью $(a)$; Электронная дифрактограмма $(b)$; Бесструктурный фрагмент аморфного микропровода $(c)$, включения фазы 2-14-1 с периодом $0.9 \mathrm{~nm}$ в аморфной матрице микропровода $(d)$.

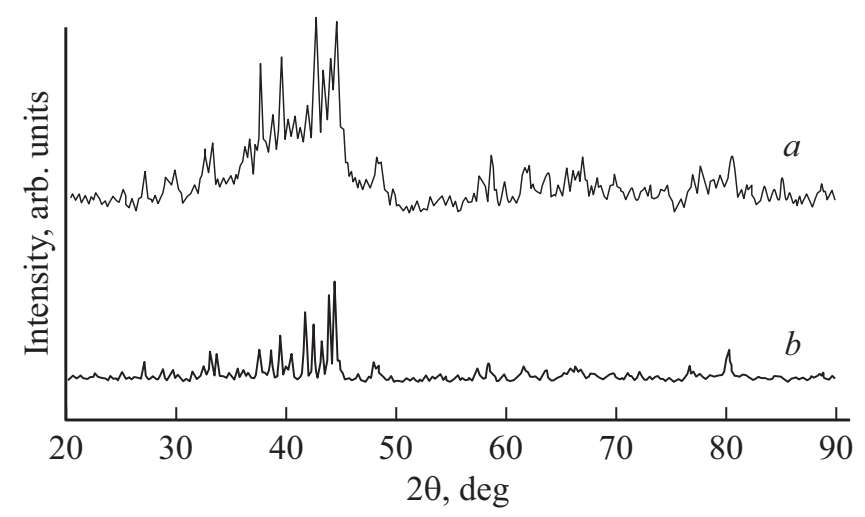

Рис. 2. Спектры рентгеновской дифракции микропроводов, до отжига $(a)$ и отожженных в вакууме при $900^{\circ} \mathrm{C}$ в течение $30 \min (b)$.

Методами энергодисперсионного анализа (EDX) и фотоэлектронной спектроскопии (XPS) был установлен химический состав микропроводов $\mathrm{Dy}_{3.5} \operatorname{Pr}_{6} \mathrm{Fe}_{49} \mathrm{Co}_{40} \mathrm{~B}_{2.5}$ (см. типичный спектр EDX на рис. 3,a). Содержание бора, не детектируемого этими методами, было рассчитано исходя из данных об атомных концентрациях остальных элементов и их вкладе в плотность материала.
Распределение элементов в поперечном и продольном сечении микропроводов было относительно равномерным, как до (рис. 3, $b, c$ ), так и после лазерного облучения (не приводится). Методом XPS были подтверждены данные о химическом составе, а анализ линий отдельных элементов (рис. 4) показал отсутствие окисления в приповерхностных слоях микропровода, о чем можно было судить по отсутствию в окрестности линий спектра известных линий оксидов металлов.

Для облучения микропроводов использовали иттербиевый ИК-лазер (Raycus, KHP) с длиной волны $1070 \mathrm{~nm}$ и максимальной средней мощностью $P \sim 20 \mathrm{~W}$. Энергия, передаваемая в одиночном импульсе, была равна $1 \mathrm{~mJ}$, что при длительности импульса 120 ns соответствовало мощности $10 \mathrm{~kW}$. Лазерное излучение было сфокусировано объективом F-100 mm в пятно радиусом $10 \mu \mathrm{m}$, что соответствовало плотности энергии в импульсе $250 \mathrm{~J} / \mathrm{cm}^{2}$. Луч лазера передвигался по заданной траектории с заданными временными параметрами с помощью системы Sino-Galvo с точностью позиционирования $\sim 7 \mu \mathrm{m}$. Траектория движения лазерного пучка была запрограммирована с помощью программного пакета EzCAD 2.9.9. Пучок двигался перпендикулярно оси микропровода со скоростью $850 \mathrm{~mm} / \mathrm{s}$, выбранной так, чтобы 

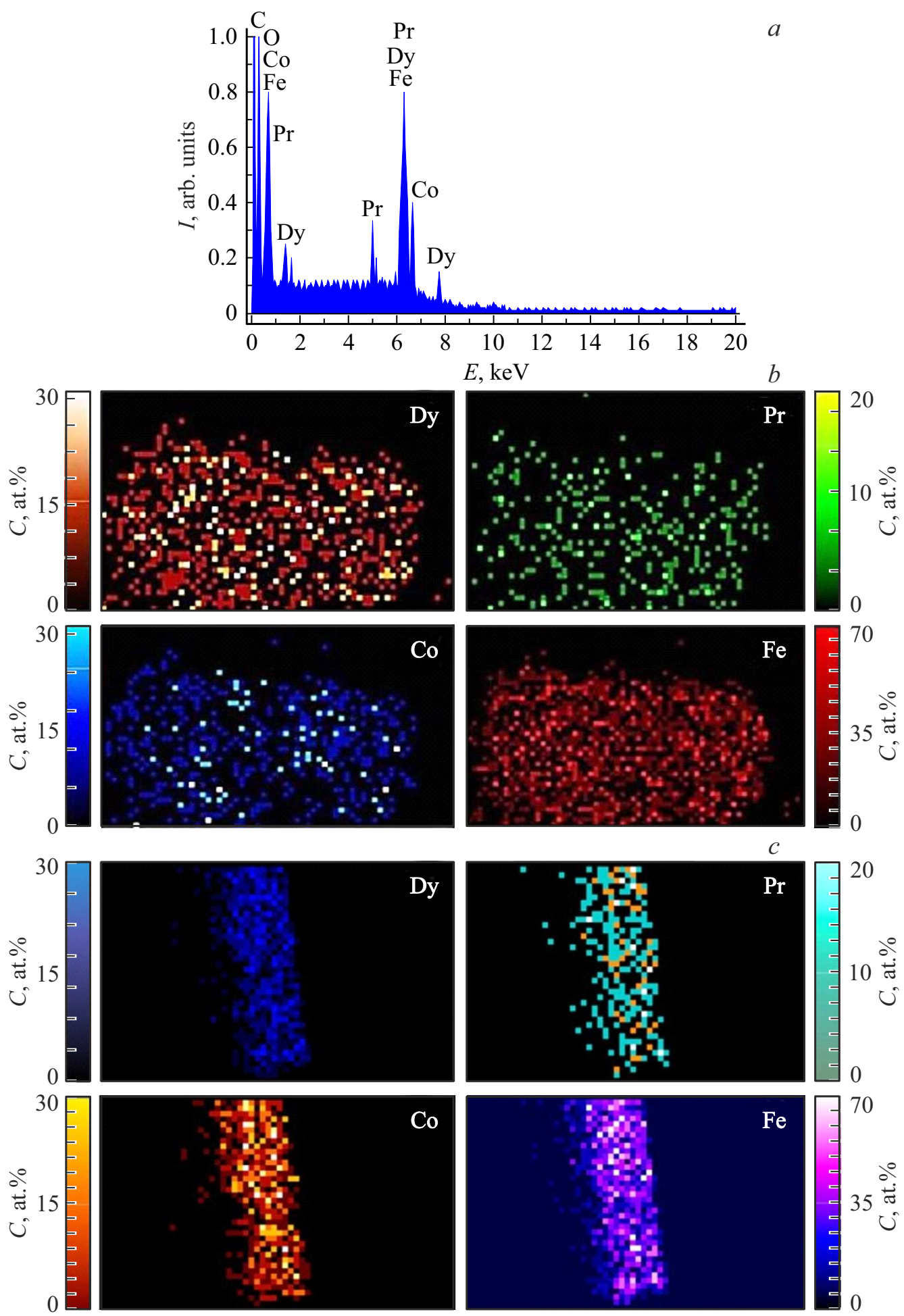

Pис. 3. Типичный энергодисперсионный спектр $\operatorname{EDX}$ в исходном микропроводе $(a)$; распределение химических элементов $\operatorname{Pr}$, Dy, $\mathrm{Co}, \mathrm{Fe}$ в поперечном сечении микропровода $(b)$ и вдоль его длины $(c)$.

при частоте следования импульсов $25 \mathrm{kHz}$ микропровод подвергался действию только одного импульса облучения. При таком движении луч лазера оставлял на подложке серию ямок, разделенных расстоянием $\sim 30 \mu \mathrm{m}$, сравнимым с диаметром микропровода 50-100 $\mu \mathrm{m}$.
Для анализа локальных магнитных свойств в местах микропровода, подвергнутых лазерному облучению, были использованы два магнито-оптических метода при 290 К. Метод магнитоиндикаторных пленок (MOIF) (см. подробное описание в [20]) позволял наблюдать вариа- 

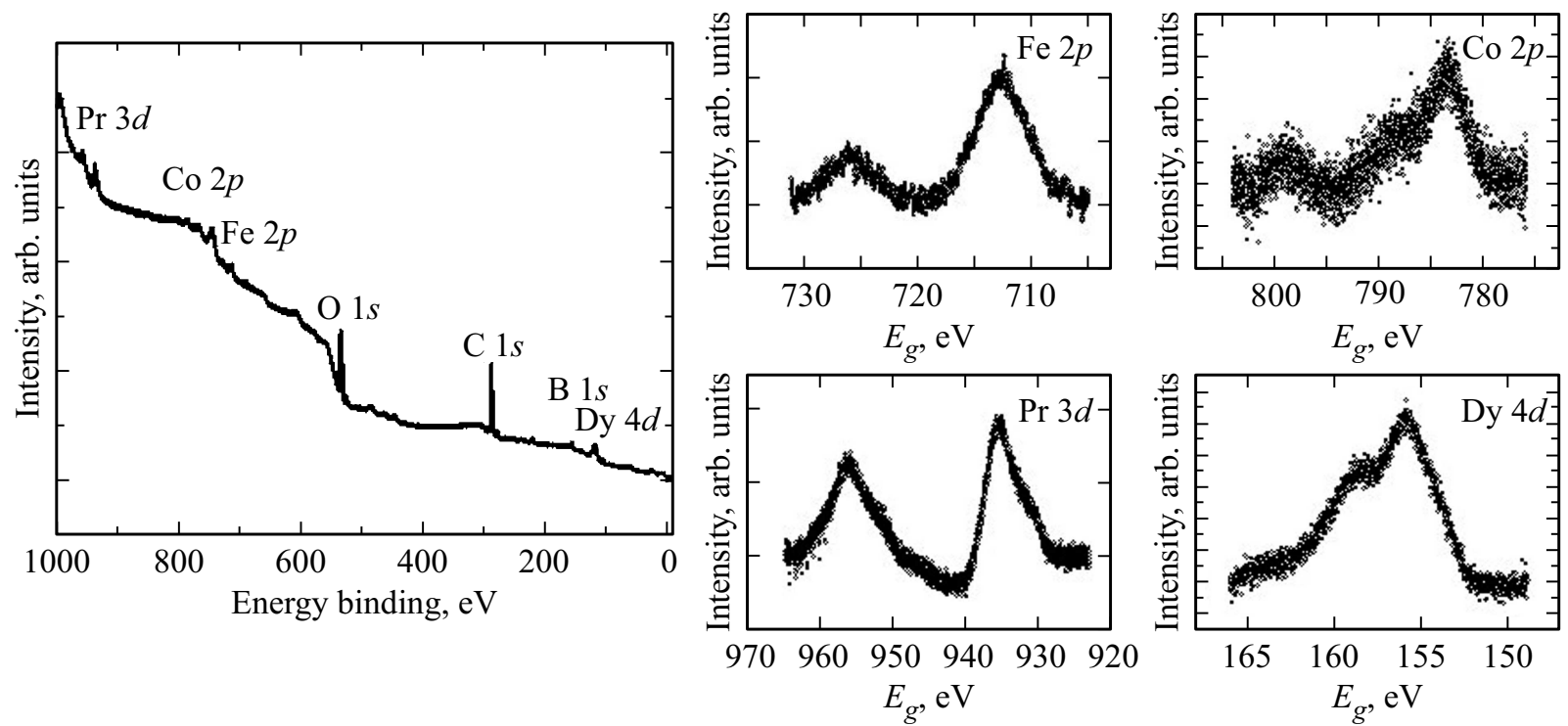

Pис. 4. Спектр фотоэлектронной спектроскопии исходного микропровода (XPS-спектр) и фрагменты спектра, соответствующие ионам $\mathrm{Fe}, \mathrm{Co}$, Pr и Dy.
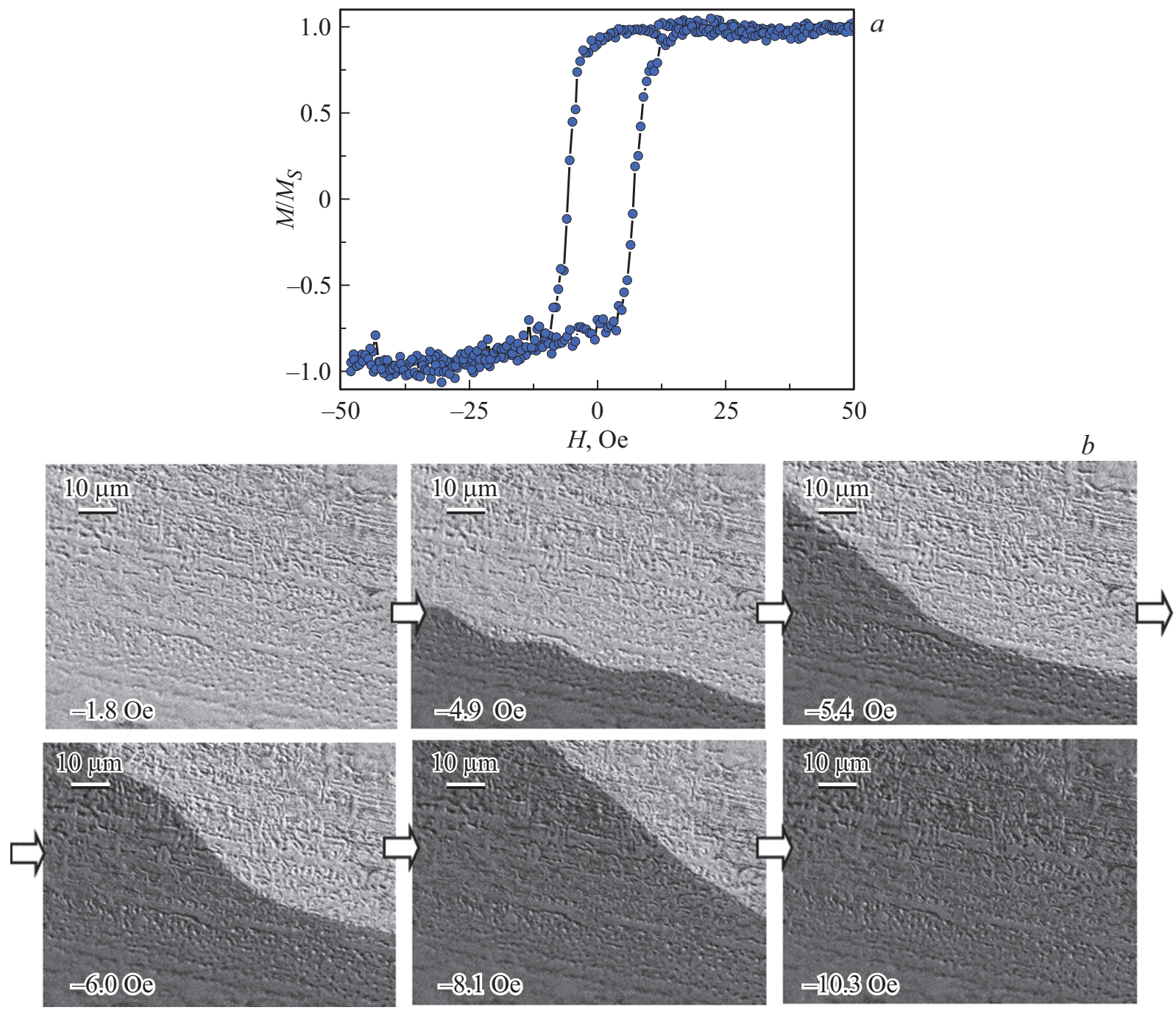

Pис. 5. (a) Локальная петля магнитного гистерезиса микропровода, полученная с помощью микроскопа Керра на участке его поверхности до отжига; $(b)$ Изменение доменной структуры при уменьшении поля в отрицательном диапазоне от -1.8 до -10.3 Oe. 


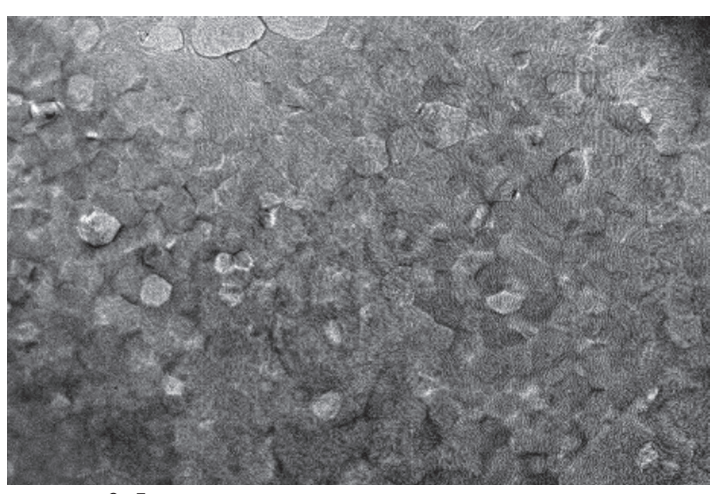

$-0.5 \mu \mathrm{m}$
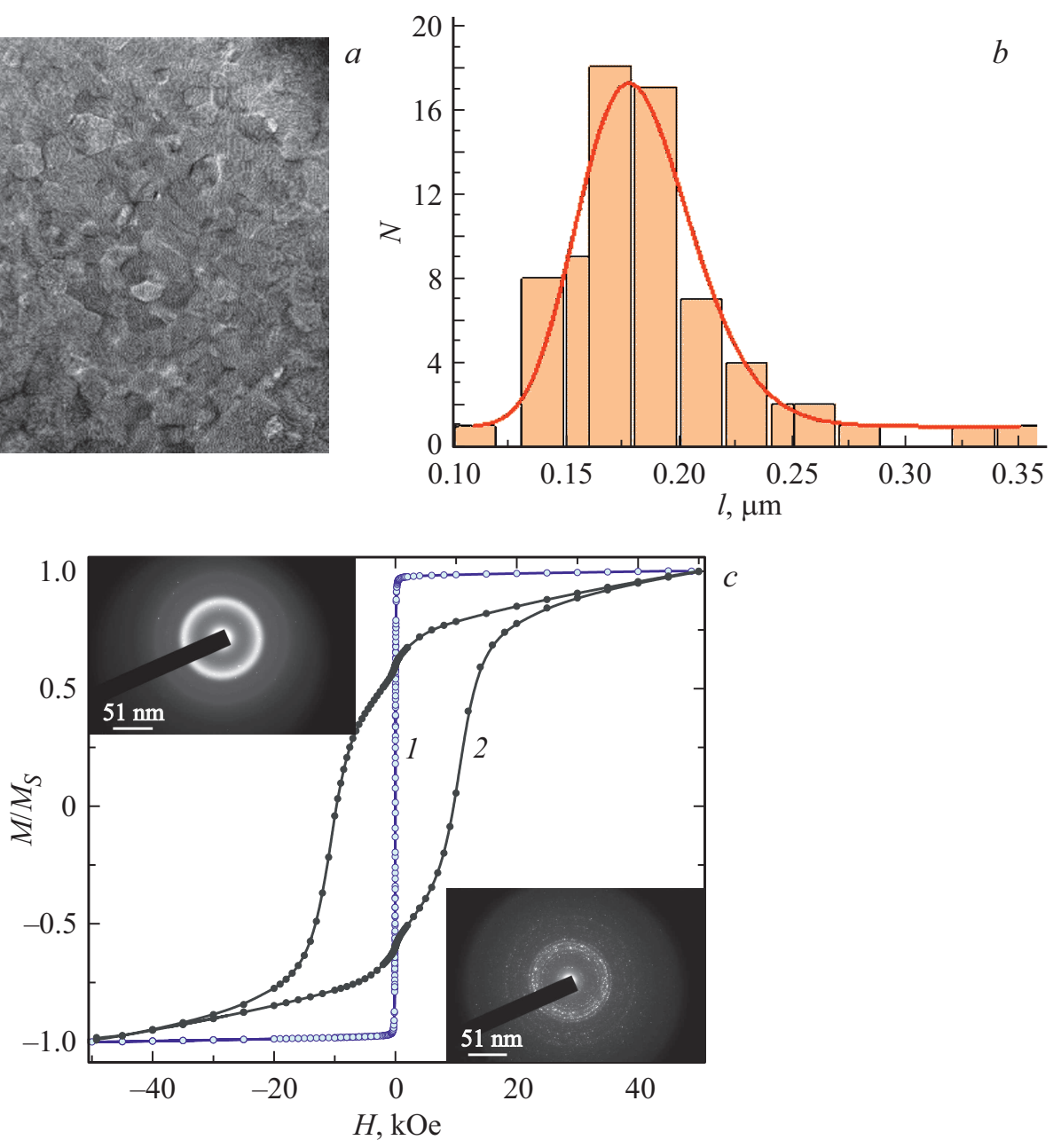

Рис. 6. (а) Поликристаллическая структура микропровода, отожженного при $900^{\circ} \mathrm{C}$ в течение 30 min, выявленная ТЕМ; (b) распределение размера микрокристаллов в отожженном микропроводе (сплошной линией показана аппроксимация логнормальным распределением с центром при $0.18 \mu \mathrm{m} ;(c)$ петли гистерезиса магнитного момента, нормированного на намагниченность насыщения для исходного микропровода (1) и микропровода, отожженного при $900^{\circ} \mathrm{C}$ в течение 30 min $(2)$. Соответствующие электронные дифрактограммы показаны на врезках вверху для исходного микропровода, внизу - для отожженного микропровода.

ции перпендикулярной составляющей намагниченности микропровода по изменению поворота плоскости поляризации поляризованного света, отраженного от иттриевой пленки на поверхности провода. Микроскопия продольного эффекта Керра и получение локальных петель магнитного гистерезиса осуществлялись с помощью микроскопа Keppa NEOARK Neomagnesia Lite BH-753 c магнитным полем до 1 кОе, направленным вдоль главной оси микропровода. Интегральный магнитный момент микропровода и его зависимости от поля были записаны в SQUID-магнетометре MPMS XL Quantum design при $300 \mathrm{~K}$.

Исследование температур фазовых превращений проводили на синхронном термическом анализаторе STA 449 F3 Jupiter NETZSCH-Gerätebau GmbH (Германия). Навеску микропроводов $\sim 0.5-1.5 \mathrm{mg}$ помещали в тигли из оксида алюминия. Нагрев проводили со скоростью $40 \mathrm{~K} / \mathrm{min}$ в потоке гелия $100 \mathrm{ml} / \mathrm{min}$ в диапазоне температур $30-1300^{\circ} \mathrm{C}$.

\section{3. Результаты и обсуждение}

\section{1. Влияние длительного вакуумного отжига на структуру и магнитные свойства микропроводов}

В исходном аморфном микропроводе наблюдается небольшой гистерезис намагниченности с коэрцитивной силой около $10 \mathrm{Oe}$ (рис. 5,a). При этом наблюдается движение доменных стенок, и перемагничивание происходит расширением доменов (рис. $5, b$ ). Наличие гистерезиса и доменных стенок в аморфном ферромагнетике, как известно, связано с неоднородностью микропровода и центрами закрепления доменных стенок в виде неоднородностей и дефектов поверхности [21].

Отметим, что рис. 5 получен в магнитном поле, направленном вдоль оси микропровода, а конфигурация микроскопа Керра с углом падения луча к поверхности 
$\sim 45^{\circ}$ обеспечивала регистрацию продольной намагниченности микропровода (L-MOKE).

Для последующего сравнения со свойствами микропроводов, подвергнутых облучению лазером, сначала были проведены эксперименты, в которых изучали изменение структуры и магнитных свойств исходно аморфных микропроводов под действием отжига при темпеpaтуре $900^{\circ} \mathrm{C}$ в ваккумной печи $\left(10^{-6}\right.$ bar $)$ в течение 30 min. Как уже было отмечено, такой отжиг устраняет гало на спектрах рентгеновской дифракции, которое связано с наличием аморфной и/или нанокристаллической фазы сплава (рис. 2). Кроме того, вместо аморфного (рис. $1, c)$ или нанокристаллического (рис. $1, d)$ состояний в отожженном микропроводе возникает поликристаллическая структура (рис. 6,a), в которой средний размер кристаллита составляет $l=0.18 \mu \mathrm{m}$ (см. распределение зерен по размерам $l$ на рис. $6, b)$.

Смена сплошных колец электронной дифракции на отдельные рефлексы (см. врезки на рис. 6,c) свидетельствует о превращении аморфно-нанокристаллического состояния микропроводов в поликристаллическую структуру. Эти изменения, вызванные термическим отжигом, сопровождаются значительным изменением магнитных свойств. Вместо очень узкой петли гистерезиса с коэрцитивной силой менее $10 \mathrm{Oе}$, в том же микропроводе возникает широкая петля гистерезиса с коэрцитивной силой 1.5 Т. При этом наблюдается ступенчатый характер петли, что свидетельствует о наличии в микропроводе одновременно двух фаз: магнитожесткой фазы 2-14-1 и магнитомягких фаз типа 1-4-1, 2-1 и др.

Идентификация фаз, кристаллизующихся из аморфного состояния при лазерном нагреве возможна путем независимой регистрации фазовых превращений методом дифференциальной сканирующей калориметрии (ДСК). На рис. 7 представлены результаты ДСК для навески микропроводов $0.5 \mathrm{mg}$, не подвергавшихся отжигу.

Положительное направление вертикальной оси на рис. 7. соответствует выделению тепла (экзотермическому процессу). Видно, что имеют место два экзотермических процесса (максимумы 1 при $965^{\circ} \mathrm{C}$ и 2 при $991^{\circ} \mathrm{C}$ ) и четыре эндотермических процесса (минимумы 3 (при $1066^{\circ} \mathrm{C}$ ), 4 (при $1096^{\circ} \mathrm{C}$ ), 5 (при $1118^{\circ} \mathrm{C}$ ) и процесс 6 при $1200^{\circ} \mathrm{C}$, отвечающий расплавлению микропровода). Согласно литературным данным [22], максимум 1 при $965^{\circ} \mathrm{C}$ может соответствовать образованию фазы $\mathrm{PrCo}_{2}$ из аморфной фазы (в литературе этот экзотермический процесс зарегистрирован при $938^{\circ} \mathrm{C}$ для $\mathrm{NdFeB}$ ). Максимум 2 при $991^{\circ} \mathrm{C}$ может отвечать экзотермическому твердофазному процессу образования фазы Лавеса 2-1. Минимум 3 при $1066^{\circ} \mathrm{C}$ близок к температуре $1065^{\circ} \mathrm{C}$, которая соответствует расплавлению фазы $\mathrm{PrCo}_{3}$ (фаза 1-3). Минимум 4 при $1096^{\circ} \mathrm{C}$ близок к температуре плавления фазы 1-4-1, (например, температура плавления $\operatorname{PrCo} 4 \mathrm{~B}$ равна $1107^{\circ} \mathrm{C}$ ). Минимум 5 при $1118^{\circ} \mathrm{C}$ может отвечать фазе 2-14-1, температура плавления которой для $\operatorname{Pr}_{2} \mathrm{Co}_{14} \mathrm{~B}$ равна $1135^{\circ} \mathrm{C}$. Таким

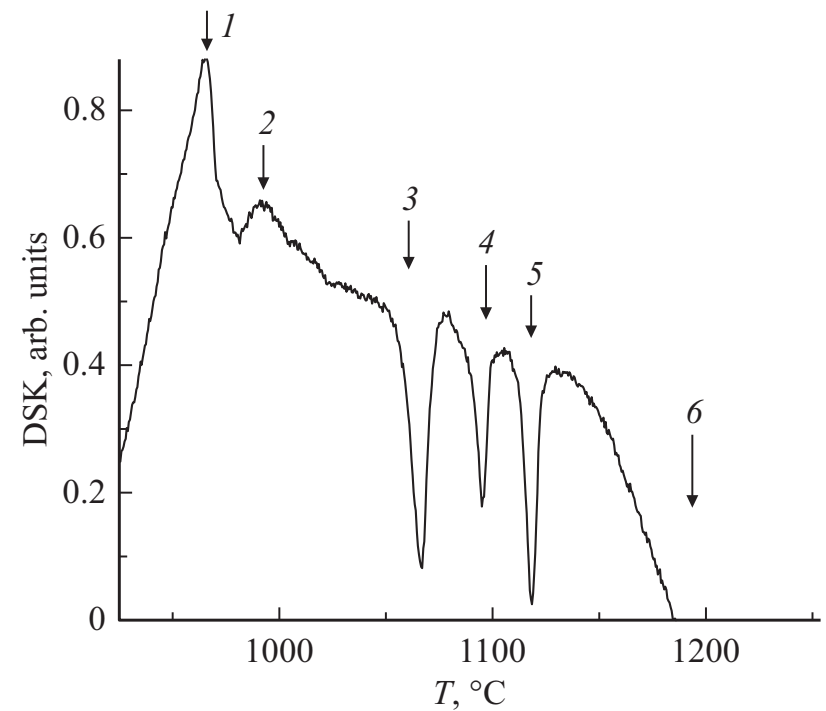

Рис. 7. Температурная зависимость сигнала дифференциальной сканирующей калориметрии в отдельном микропроводе. Стрелками отмечены переходы 1-6, наблюдаемые в микропроводе при различных температурах, обсуждаемых в тексте. Положительное направление вертикальной оси соответствует выделению тепла (экзотермическому процессу).

образом, постепенный нагрев аморфных микропроводов ведет к серии последовательных процессов твердофазных превращений в кристаллические фазы 1-2 и 2-1 с выделением тепла, а также к плавлению фаз 1-3, 1-4-1, 2-14-1 с выделением тепла.

\section{2. Локальное изменение структуры и магнитных свойств участков микропровода, подвергнутых лазерному облучению}

Изображение микропровода на подложке, подвергнутого лазерному облучению приведено на рис. $8, a$. Видны следы оплавления на поверхности микропровода, чередующиеся вдоль его длины с периодом $120 \mu \mathrm{m}$. Размеры области, модифицированной лазером на поверхности микропровода $\sim 20-30 \mu \mathrm{m}$ превышают размер светового пятна $15 \mu \mathrm{m}$. О размере светового пятна можно судить по круглым отметкам, оставленным сканирующим лазером на подложке из скотча (рис. $8, a)$.

Расстояние между этими отметками $30 \mu \mathrm{m}$ соответствует скорости движения пятна и частоте импульсов лазера. Видно, что при диаметре микропровода 50-70 $\mu \mathrm{m}$ не более одного импульса лазера могло попасть на его поверхность при поперечном проходе.

Для установления того, какие изменения в магнитном состоянии микропровод были вызваны лазерным облучением, на микропровод накладывалась тонкая пленка иттриевого граната с зеркальным покрытием, отражение поляризованного света от которой зависело от перпендикулярной намагниченности этой индикаторной 


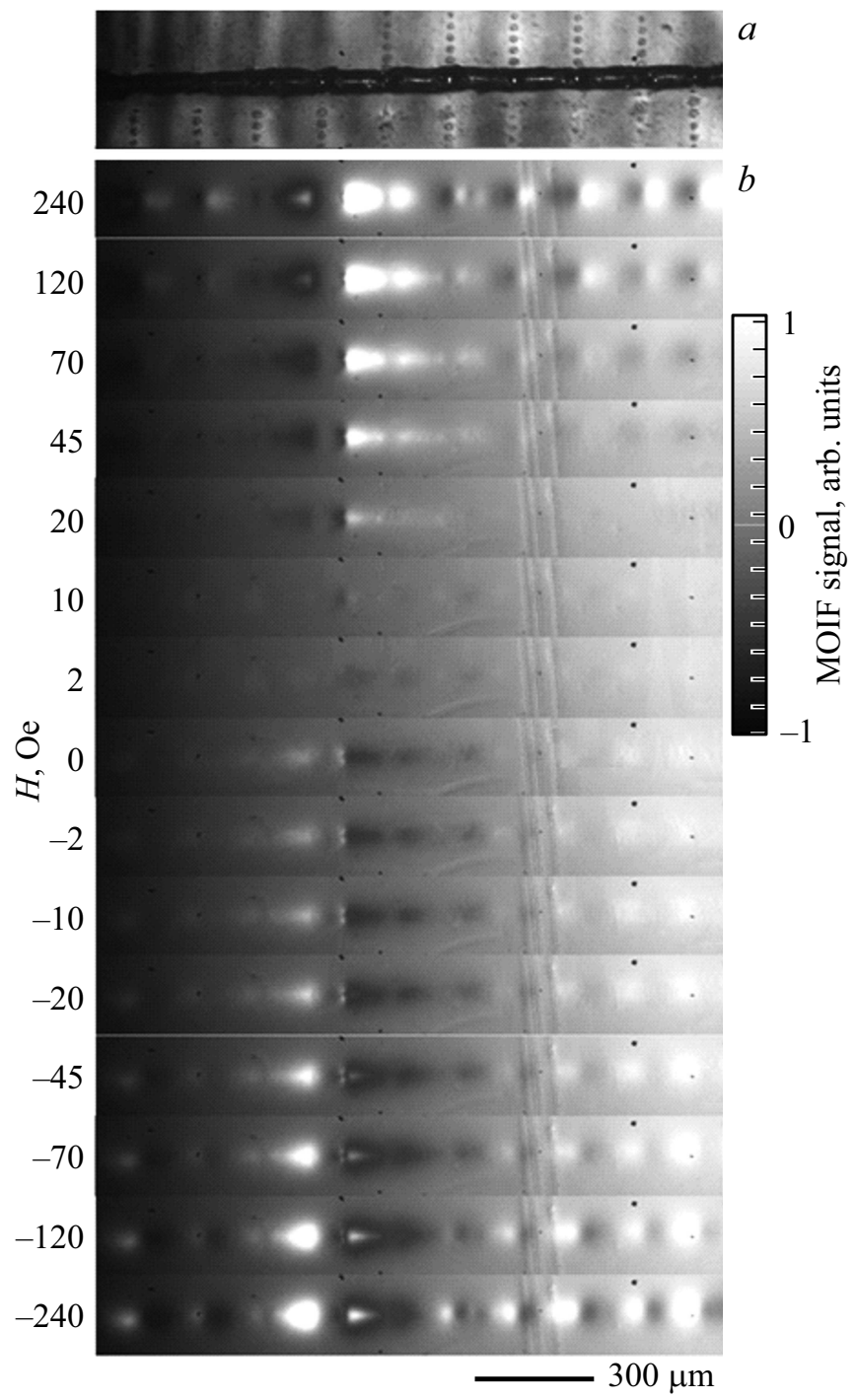

Рис. 8. (a) Оптическая фотография микропровода, облученного импульсом лазера, в режиме сканирования поперек микропровода. Пунктирные следы одиночных лазерных импульсов указывают периодичность импульса $40 \mu \mathrm{s}$; (b) Распределение радиальной составляющей намагниченности в лазерно-индуцированных магнитных картинах, выявленных методом MOIF. Слева показана величина продольного магнитного поля.

пленки. В этих условиях, наблюдение контраста в поляризационный оптический микроскоп позволяло регистрировать вариации перпендикулярной намагниченности микропровода в виде темных и светлых пятен, которые отвечали участкам пленки иттриевого граната, находящимся в разном поле рассеяния, создаваемом магнитными неоднородностями микропровода (контраст MOIF). На рис. $8, b$ показаны изображения, полученные таким образом в различных внешних полях, приложенных вдоль оси микропровода. Эти изображения в продольном поле представляют собой чередующиеся темные и светлые контрасты. Магнитный диполь, характеризующийся сочетанием темных и светлых зон, имеет центр, совпадающий с центром участка, облученного лазером. Количество диполей, сформированных облучением, не зависит от внешнего поля - меняется лишь их яркость по мере увеличения поля. Отметим, что продольное магнитное поле не влияло на намагниченность индикаторной пленки, а могло лишь намагничивать микропровод. Поэтому вариации магнитного рельефа перпендикулярной компоненты поля рассеяния микропровода на рис. $8, b$ характеризуют особенности его магнитной структуры. Отметим, что шероховатость оплавленных участков микропровода была сравнима с шероховатостью его необлученных фрагментов. Поэтому наличие темных и светлых областей на изображениях MOIF не может быть объяснено измененной лазером топографии поверхности микропровода. Таким образом, изображения MOIF показывают, что участки, облученные лазером, обладают иными магнитными свойствами, по сравнению с исходным аморфным материалом того же микропровода.

Исследование ламелей, вырезанных из облученных участков микропровода с помощью электронной дифракции в ТЕМ-микроскопе (рис. 9, $a$ ) показывает, что их структура значительно отличается от исходной аморфной (рис. $1, c)$ и нанокристаллической (рис. $1, d$ ) структуры микропровода.

На рис. 9 видна поликристалличность присутствие зерен с разными периодами кристаллической решетки $14.81,12.92,7.4 \AA$. Электронограмма облученных лазером областей не содержит сплошного гало, свойственного аморфному состоянию, а характеризуется большим количеством дискретных рефлексов. Обработка этих рефлексов показывает, что в облученных областях присутствуют нанокристаллические включения фаз 2-14-1, 4-4-1, 2-1. Эти же фазы дают вклад в пики на температурной зависимости ДСК сигнала (рис. 7). Это позволяет заключить, что локальный лазерный нагрев микропровода вызывает кристаллизацию тех же фаз, что и при макроскопическом нагреве в дифференциальном калориметре, однако, при этом вместо микрокристаллической структуры с размером зерен $l=0.18 \mu \mathrm{m}$ возникает нанокристаллическая структура. Это объясняет, почему лазерный нагрев не приводит к появлению значительной коэрцитивной силы, сопоставимой с той, которая достигается при вакуумном длительном отжиге всего микропровода 1.5 Т. Хорошо известно, что в магнитах группы $R e-T M$-В уменьшение среднего размера зерна вплоть до $l=0.2-0.3 \mu \mathrm{m}$ увеличивает коэрцитивную силу, а при дальнейшем уменьшении $l$ коэрцитивная сила резко падает [19]. Величина $l=0.2-0.3 \mu \mathrm{m}$ примерно равна пределу однодоменности в материалах группы $R e-T M$-В. Дальнейшее уменьшение размеров до $l=10-20 \mathrm{~nm}$, как это имеет место в облученных лазером областях (рис. 9, $a$ ), приводит к резкому падению коэрцитивной силы вместе с полем магнитной анизотропии $H_{A}$, убывающим вместе с объемом зерна. Таким образом, несмотря на формирование основной ферромагнитной фазы 2-14-1 в облученных лазером участках размеры 

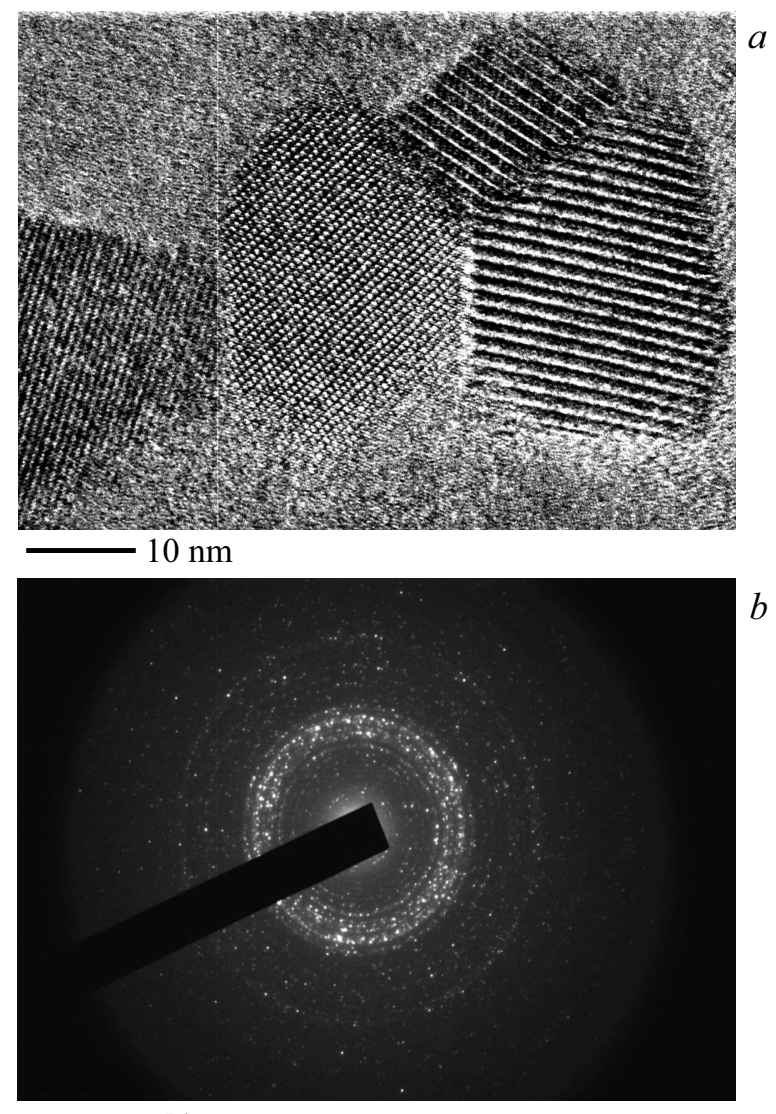

$51 \mathrm{~nm}$

Рис. 9. (a) ТЕМ-изображение участка микропровода, подвергнутого лазерному облучению; $(b)$ электронная дифрактограмма микропровода, подвергнутого лазерному облучению.

ее зерен оказались слишком малы, что повлекло за собой малую коэрцитивную силу $\sim 40-50$ Ое, которая оказалась все же больше, чем в исходном микропроводе или в его необлученных участках.

Чтобы проанализировать локальное изменение магнитных свойств, мы провели измерения продольной намагниченности микропровода с помощью микрокопа Керра (рис. 10,a). На врезках к рис. 10, $a$ показаны фрагменты поверхности микропровода, выделенные прямоугольниками на участках облученных и необлученных лазером. Запись петли гистерезиса намагниченности, нормированной на ее значение в сильном поле, показывает, что в облученном участке насыщение намагниченности достигается в поле $H_{A}=500 \mathrm{Oe}$, большем, чем в необлученном участке того же образца (рис. 10,a).

Поскольку намагниченность насыщения микропровода $M_{S}$ была одинакова до и после его облучения, можно считать, что вклад анизотропии формы в поле магнитной анизотропии $H_{A}$ не изменился после облучения лазером. Следовательно, поле насыщения в облученных участках микропровода можно воспринимать, как результат появления магнито-кристаллической анизотропии величиной 500 Oе. Для родственного сплава этот результат хорошо известен. В [19] для сплава DyFeB было установлено, что при размере зерен в нем $7.9 \mathrm{~nm}$ коэрцитивная сила составляет всего 400 Ое, тогда как при размере зерен $l=1.3 \mu \mathrm{m}$ она превышает $1.5 \mathrm{~T}$, что весьма сходно с результатами, полученными в нашей работе.

Мы также измеряли полевую зависимость интегрального магнитного момента целого провода в СКВИД магнетометре до и после его облучения (рис. $10, b)$. Хотя лишь треть участков микропровода была подвергнута облучению, более плавное насыщение намагниченности было обнаружено также и при сравнении полевых зависимостей $M / M_{s}(H)$, полученных в интегральных измерениях (рис. $10, b$ ). Причем поле $H_{A}=500$ Ое, в котором пересекаются зависимости $M / M_{s}(H)$, полученные
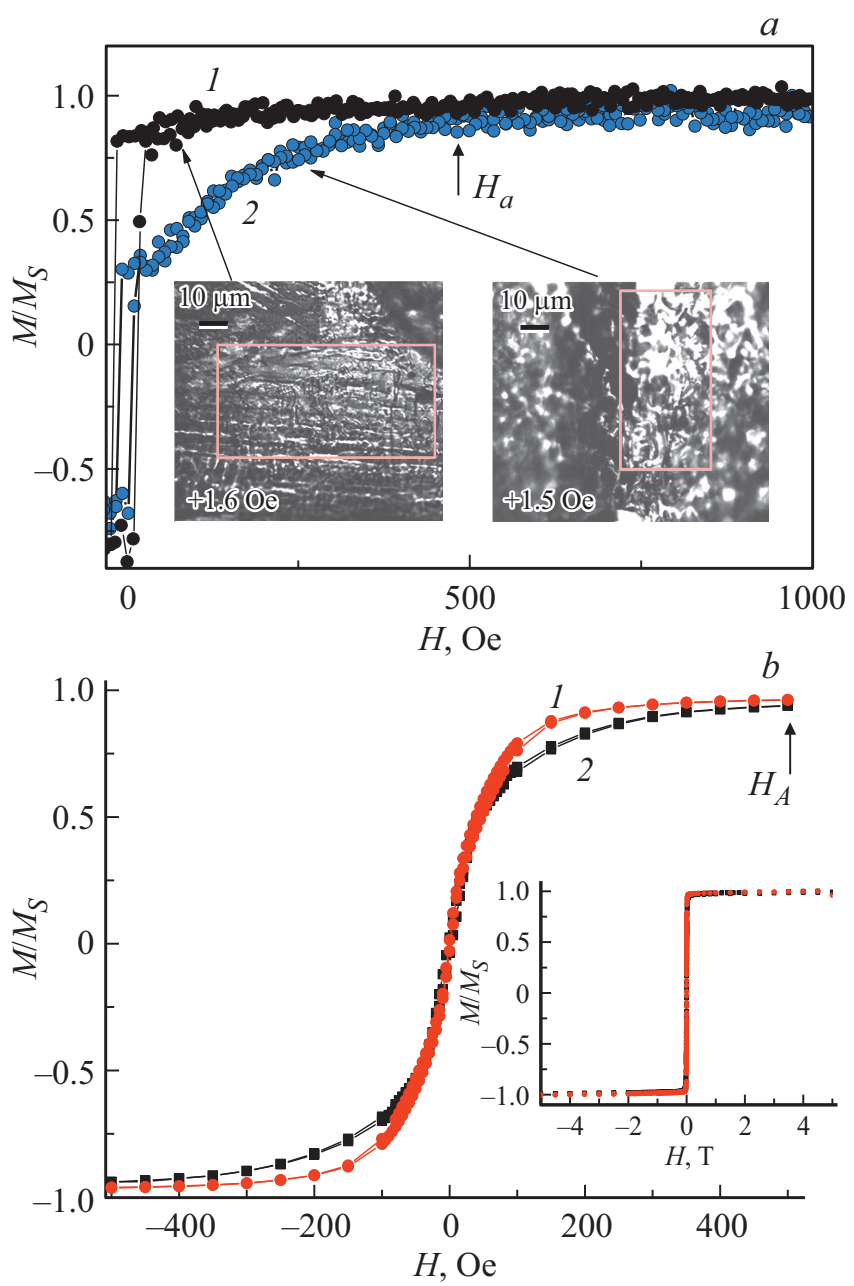

Рис. 10. (a) Петли гистерезиса локальной намагниченности одного и того же микропровода в областях размером $10 \times 20 \mu \mathrm{m}^{2}$ (показаны на врезках), не подвергавшимся облучению (1) и подвергнутых лазерному облучению (2); (b) петли гистерезиса намагниченности целого микропровода, нормированные на намагниченность насыщения до лазерного облучения (1), и после лазерного облучения (2). На врезке показаны эти же зависимости в увеличенном масштабе. Стрелкой отмечено значение поля анизотропии в облученном микропроводе. 
до и после облучения одного и того же микропровода, оказалось близко к полю, определенному локальным измерением в рамках микроскопии Керра (рис. 10, b).

\section{4. Выводы}

1. Получены аморфные микропровода $\mathrm{DyPrFeCoB}$ c небольшой долей (10-20\%) нанокристаллических включений фазы 2-14-1. Коэрцитивная сила этих микропроводов 5-10 Ое близка к нулю. Отжиг микропроводов при $900^{\circ} \mathrm{C}$ в течение $30 \mathrm{~min}$ ведет к твердотельному превращению аморфного материала в кристаллические фазы 1-2 и 2-1 с выделением тепла, а также к плавлению фаз 1-3, 1-4-1, 2-14-1 с выделением тепла. В результате вакуумного длительного отжига структура микропровода становится поликристаллической со средним размером зерна $0.18 \mu \mathrm{m}$, а петля магнитного гистерезиса уширяется до коэрцитивной силы $1.5 \mathrm{~T}$, которая характеризует появление фазы 2-14-1 наряду с магнитомягкими фазами 1-2 и 2-1. Сосуществование мягкой и жесткой магнитных фаз приводит к ступенчатой форме петли гистерезиса.

2. Локальный отжиг одиночным импульсом ИК-лазером не эквивалентен вакуумному отжигу. Он приводит к превращению аморфного материала микропровода в нанокристаллическую структуру со средним размером зерна 20-30 nm в областях размером 20-30 $\mu \mathrm{m}$. Ферромагнитные фазы, полученные коротким лазерным отжигом из аморфного материала, имеют низкую коэрцитивную силу, близкую к нулю, но увеличенное поле кристаллической анизотропии 500 Ое. Несмотря на формирование фазы 2-14-1, размеры ее кристаллитов 10-20 nm оказываются слишком малы, чтобы формировать сколько-нибудь заметную коэрцитивную силу, однако увеличенное поле магнитной анизотропии является признаком формирования ферромагнитной фазы.

3. С помощью лазерного локального отжига получены магнито-модулированные периодические структуры, в которых нанокристаллические ферромагнитные участки чередуются с аморфным материалом. Перпендикулярная составляющая полей рассеяния участков, кристаллизованных под действием лазерного облучения, может быть использована для инженерии микромагнитов.

\section{Благодарности}

Авторы выражают искреннюю благодарность Н.Н. Дремовой и И.И. Ходосу за помощь в получении SEM и ТЕМ-изображений.

\section{Финансирование работы}

Работа выполнена в рамках тематической карты Института проблем химической физики АААА-А19119092390079-8, при поддержке проекта РФФИ (грант 20-32-70025) и программы грантов Президента РФ для поддержки ведущих научных школ (грант 2644.2020.2).

\section{Конфликт интересов}

Авторы заявляют, что у них нет конфликта интересов.

\section{Список литературы}

[1] H. Peng, F. Qin, M. Phan. Ferromagnetic Microwire Composites From Sensors to Microwave Applications. Springer, Cham, Switzerland (2016). 245 p.

[2] M. Vazquez. Magnetic Nano- and Microwires, Design, Synthesis, Properties and Applications. 1st ed. Woodhead Publishing, UK, Cambridge, (2015). 962 p.

[3] V. Zhukova, P. Corte-Leon, M. Ipatov, J.M. Blanco, L. Gonzalez-Legarreta, A. Zhukov. Sensors 19, 4767 (2019).

[4] S. Wang, Y. Liang, F. Ye, G. Geng, J. Lin. J. Mater. Proc. Tech. 249, 325 (2017)

[5] V. Zhukova, M. Ipatov, J.J. Val, A. Granovsky, A. Zhukov. IEEE Trans. Magn. 54, 1 (2018).

[6] I. Vlaminck, C. Dekker. Ann. Rev. Biophys. 41, 453 (2012).

[7] J. Jaćimović, F. Binda, L.G. Herrmann, F. Greuter, J. Genta, M. Calvo, T. Tomeš, R.A. Simon. Adv. Eng. Mater. 19, 1700098 (2017).

[8] M.A. Alubaidy, K. Venkatakrishnan, B. Tan. Nano. Res. Lett 6, 375 (2011).

[9] R.B. Morgunov, O.V. Koplak, V.P. Piskorskii, D.V. Korolev, R.A. Valeev, A.D. Talantsev. J. Magn. Magn. Mater 497, 166004 (2020)

[10] R.B. Morgunov, O.V. Koplak. Mater. Sci. Eng. B 263, 114845 (2021).

[11] R.B. Morgunov, O.V. Koplak. Mater.Lett. 273, 127954 (2020).

[12] V. Popov, A. Koptyug, I. Radulov, F. Maccaric, G. Muller. Proc. Manufactur. 21, 100 (2018).

[13] A. Walther, C. Marcoux, B. Desloges, R. Grechishkin, D. Givord, N. Dempsey. J. Magn. Magn. Mater. 321, 590 (2008).

[14] J.J. Croat, A.R. Chraplyvy, J.F. Herbst. Appl. Phys. Lett. 37, 962 (1980).

[15] R. Molian, P. Molian. J. Magn. Magn. Mater. 321, 241 (2009).

[16] B. Guo. Chin. Mater. Conf., Proc. Eng. 27, 671 (2011).

[17] K. Chu, Z.Q. Jin, V.M. Chakka, J.P. Li. J. Phys. D 38, 4009 (2005).

[18] T. Harada, M. Fujita, T. Kuji. Nucl. Instrum. Meth. Phys. Res. B 12, 383 (1997).

[19] M. Yue, R.M. Liu, W.Q. Liu, D.T. Zhang, J.X. Zhang, Z.H. Guo, W. Li. IEEE Trans. Nanotech. 11, 651 (2012).

[20] V.I. Nikitenko, V.S. Gornakov, L.M. Dedukh, A.F. Khapikov, L.H. Bennett, h.D. McMichael, L.J. Swartzendruber, A.J. Shapiro, M.J. Donahue. J. Appl. Phys. 79, 6073 (1996).

[21] H. Kronmüller, B. Gröger. J. de Phys. 42, 1285 (1981).

[22] M.-A. Van Ende, I.-H. Jung, Y.-H. Kim, T.-S. Kim. Green. Chem. 17, 2246 (2015).

Редактор Т.Н. Василевскал 